\title{
Touching the Membranous Septum: A Thin Line between Treating and Threatening?
}

\author{
Harilaos Bogossian ${ }^{a, b}$ Nana-Yaw Bimpong-Buta ${ }^{a}$ Patrick Müller ${ }^{c}$ \\ ${ }^{a}$ Department of Cardiology and Rhythmology, Evangelisches Krankenhaus Hagen, Hagen, Germany; ${ }^{\text {b Department }}$ \\ of Cardiology, Witten/Herdecke University, Witten, Germany; ' ${ }^{C}$ Department of Cardiology II - Electrophysiology, \\ Universitätsklinikum Münster, Münster, Germany
}

The article by Stachon et al. [1] is an important contribution because it highlights the impact of diverse calcification patterns on the conduction system of the heart after transcatheter aortic valve replacement (TAVR). In this regard, the cardiologists of the University of Freiburg performed focused multi-sliced computed tomography for the preprocedural assessment of valve morphology and the valve calcification status on the one hand, and the possible effects on an occasional - yet clinically critical complication: "postprocedural AV block."

The impact of aortic valve calcification (in particular, its volume, distribution and localization) has been investigated regarding the occurrence of high-degree AV conduction block and the consecutive need for postprocedural pacemaker (PM) implantation. Prior anatomical and electrophysiological studies showed the close topographic relation of the membranous septum to the atrioventricular node and the bundle of His, respectively [2, 3]. Likewise, the topographies of fundamental anatomical structures in the right-sided heart chambers, particularly within the triangle of Koch, have been very well described, the knowledge of which is the framework for established electrophysiological procedures such as slow-pathway ablations in patients with atrioventricular node re-en- trant tachycardia. For instance, in the era of His bundle and left bundle pacing, this knowledge has proven useful [4-7].

In prior investigations pertaining the affection of the conduction system in the course of ablation and pacing procedures, alternative procedural access routes, such as left-sided access, have become popular [8,9]. In these scenarios, the intraprocedural anatomical adjacencies to the right coronary and noncoronary cusps of the aortic valve have been of concern. Due to the anatomical proximity of the abovementioned anatomical structures, notably in TAVR, inherent procedural maneuvers entailing overstretching of the left ventricular outflow tract may cause accidental affection of the conduction system, as is commonly seen during balloon dilatation in TAVR.

This effect might become even more prominent with deeper implantation levels and oversizing of the implemented valve prosthesis, respectively [10]. Alas, in patients with relevant annular calcification, the risk of this effect is even tripled [11].

Commentary on Stachon et al. "Impact of Preprocedural Aortic Valve Calcification on Conduction Disturbances after Transfemoral Aortic Valve Replacement." karger@karger.com

www.karger.com/crd

Karger!
(C) 2020 S. Karger AG, Basel
Harilaos Bogossian

Department of Cardiology and Rhythmology

Evangelisches Krankenhaus Hagen, Brusebrinkstrasse 20

DE-58135 Hagen (Germany)

bogossianh@esv.de 
In the setting of TAVR, in the light of procedural planning, calcification of the aortic valve is a boon and a bane: on the one hand, it can aid in adequate fixation of the prosthesis, whereas, on the other hand, conduction disturbances may lie in wait.

Bearing this in mind, the present study by Stachon et al. [1] focused on two substantial characteristics of annular valve calcifications: their shape and their orientation. Here, the main finding is that an evaluation of the orientation of calcification has more weight than an evaluation of its shape.

The rate of necessity of PM implantation due to AV block was increased when calcifications crossed the aortic annulus. In patients with this formation, AV block occurred within the first 2 days after TAVR. Even more interesting is the observation that the intensity of the effect on the conduction system seemed to correlate with the orientation of the annular calcification of the valve; in this regard, an orthogonal orientation of the annular calcification, as compared to its tangential orientation, was linked to an even fivefold higher probability of necessity of postprocedural PM implantation. In these cases of "jeopardizing" orthogonal annular valve calcifications, these were located on the contralateral side with respect to the conduction system (particularly below the left coronary cusp). As a hard tissue, the calcification remains in place even after TAVR. In fact, this calcific immobility, with its location in the region of the left coronary cusp, rather acts as a slider towards the region of the conduction system (located between the right coronary and the noncoronary cusp). Thus, one of the potential mechanisms of severe
AV conduction disturbances with consecutive necessity of PM implantation in patients with orthogonal annular calcifications could be an inferoseptal shift of TAVR, causing stress on the membranous septum with consecutive injury to the His bundle and/or the left bundle branch.

Although it is a small retrospective study, Stachon et al. [1] describe a novel mechanism of development of post-TAVR AV conduction disturbances. Without any doubt, for interventional cardiologists and physician teams in this context, a profound knowledge about these anatomical correlations of structures in the heart chambers is crucial for any procedural TAVR planning.

\section{Conflict of Interest Statement}

The authors have no conflicts of interest to declare.

\section{Funding Sources}

No funding was received.

\section{Author Contributions}

H. Bogossian: substantial contributions to the design of the manuscript; final approval of the version to be published; and agreement to be accountable for all aspects of the work. N.-Y. Bimpong-Buta: substantial contributions to the design of the manuscript, and final approval of the version to be published. P. Müller: substantial contributions to the design of the manuscript, and final approval of the version to be published.

\section{References}

1 Stachon P, Steinfurt J, van de Loo T, Trolese L, Faber T, Kaier K, et al. Impact of preprocedural aortic valve calcification on conduction disturbances after transfemoral aortic valve replacement. Cardiology. DOI: 10.1159/000509389.

2 Auffret V, Puri R, Urena M, Chamandi C, Rodriguez-Gabella T, Philippon F, et al. Conduction Disturbances after Transcatheter Aortic Valve Replacement: Current Status and Future Perspectives. Circulation. 2017 Sep; 136(11):1049-69.

3 Upadhyay GA. The Variable Arrangement of the Atrioventricular Conduction Axis within the Triangle of Koch: Millimeters Matter. JACC Clin Electrophysiol. 2020 Apr;6(4):378-81.

4 Upadhyay GA, Cherian T, Shatz DY, Beaser $\mathrm{AD}$, Aziz Z, Ozcan C, et al. Intracardiac Delineation of Septal Conduction in Left Bundle-Branch Block Patterns. Circulation. 2019 Apr;139(16):1876-88.
5 Teng AE, Lustgarten DL, Vijayaraman P, Tung R, Shivkumar K, Wagner GS, et al. Usefulness of His Bundle Pacing to Achieve Electrical Resynchronization in Patients with Complete Left Bundle Branch Block and the Relation Between Native QRS Axis, Duration, and Normalization. Am J Cardiol. 2016 Aug; 118(4):527-34.

6 Israel CW. [His bundle stimulation: is it time for routine use?]. Herzschrittmacherther Elektrophysiol. 2020 Jun;31(2):101-3.

7 Israel CW, Tribunyan S, Kalyani M. [His bundle pacing: troubleshooting at implantation]. Herzschrittmacherther Elektrophysiol. 2020 Jun;31(2):160-76.

8 Kaneko Y, Naito S, Okishige K, Morishima I, Tobiume T, Nakajima T, et al. Atypical FastSlow Atrioventricular Nodal Reentrant Tachycardia Incorporating a "Superior" Slow Pathway: A Distinct Supraventricular Tachyarrhythmia. Circulation. 2016 Jan;133(2):114-23.
9 Salden FC, Luermans JG, Westra SW, Weijs B, Engels EB, Heckman LI, et al. Short-Term Hemodynamic and Electrophysiological Effects of Cardiac Resynchronization by Left Ventricular Septal Pacing. J Am Coll Cardiol. 2020 Feb;75(4):347-59.

10 Franzoni I, Latib A, Maisano F, Costopoulos C, Testa L, Figini F, et al. Comparison of incidence and predictors of left bundle branch block after transcatheter aortic valve implantation using the CoreValve versus the Edwards valve. Am J Cardiol. 2013 Aug;112(4): 554-9.

11 Hein-Rothweiler R, Jochheim D, Rizas K, Egger A, Theiss H, Bauer A, et al. Aortic annulus to left coronary distance as a predictor for persistent left bundle branch block after TAVI. Catheter Cardiovasc Interv. 2017 Mar; 89(4):E162-8. 